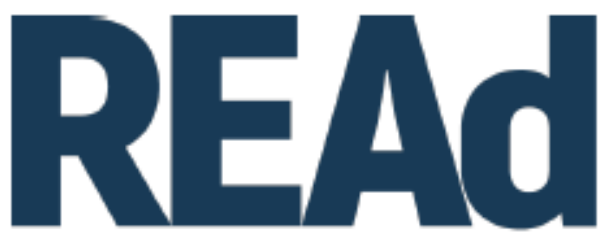

Revista Eletrônica de Administração

\title{
O TEMA DA PROSTITUIÇÃO EM PUBLICAÇÕES RELACIONADAS COM OS ESTUDOS ORGANIZACIONAIS ${ }^{1}$
}

\author{
Paulo Rodrigues Cerqueira ${ }^{2}$ \\ Maria Ceci Misoczky ${ }^{3}$
}

http://dx.doi.org/10.1590/1413-2311.306.109919

\begin{abstract}
RESUMO
Este artigo apresenta o tema da prostituição em publicações do campo dos Estudos Organizacionais. Foi realizada uma leitura interpretativa das publicações encontradas em periódicos nacionais e internacionais do campo, que resultou na organização de três conjuntos de textos. o primeiro compreende publicações que analisam a prostituição considerando aspectos relacionados à psicodinâmica; o segundo inclui textos que abordam os corpos e seus papeis em trocas que ocorrem em serviços comerciais de sexo, nos quais a prostituição está incluída; e o terceiro que compreende publicações que buscam analisar a relação da prostituição com as estruturas sociais e econômicas. Seguem as considerações finais, nas quais indicamos lacunas e potenciais desenvolvimentos.
\end{abstract}

Palavras-chave: Prostituição. Trabalho do sexo. Estudos Organizacionais.

\section{THE THEME OF PROSTITUTION IN PUBLICATIONS RELATED TO ORGANIZATION STUDIES}

\footnotetext{
${ }^{1}$ Recebido em 15/12/2020, aceito em 922021.

${ }^{2}$ Universidade Federal do Rio Grande do Sul - Programa de Pós-Graduação em Administração (PPGA); Porto Alegre (RS) - Brasil; http://orcid.org/0000-0003-3866-5174; cerqueirameister@gmail.com.

${ }^{3}$ Universidade Federal do Rio Grande do Sul - Programa de Pós-Graduação em Administração (PPGA); Porto Alegre (RS) - Brasil; correio eletrônico: http://orcid.org/0000-0003-2020-5882; maria.ceci@ufrgs.br.
} 
This article presents the theme of prostitution in publications of the field of Organization Studies. An interpretative reading of the publications found in national and international journals in the field was carried out, which resulted in the organization of three sets of texts. The first set comprises publications that analyze prostitution considering aspects related to the psychodynamics; the second includes texts that analyze bodies and their roles in exchanges occurring in commercial sex services, in which prostitution is included; and the third seeks to relate prostitution with socioeconomic structures. Follows the Final Considerations, in which we identify absences and potential developments.

Keywords: Prostitution. Sex work. Organization Studies.

\section{EL TEMA DE LA PROSTITUCIÓN EN LAS PUBLICACIONES RELACIONADAS CON LOS ESTUDIOS ORGANIZACIONALES}

Este artículo presenta el tema de la prostitución en publicaciones del campo de los Estudios Organizacionales. Se realizó una lectura interpretativa de las publicaciones encontradas en revistas nacionales e internacionales del campo, lo que resultó en la organización de tres conjuntos de textos. En el primer se encuentran publicaciones que analizan la prostitución considerando aspectos de la psicodinámica; en el segundo se encuentran textos que analizan los cuerpos y sus roles en intercambios que ocurren en servicios comerciales de sexo, en los cuales se incluye la prostitución; el tercer conjunto busca relacionar las modalidades de prostitución con estructuras socioeconómicos. Siguen las Consideraciones Finales, en las cuales se identifican lacunas y desarrollos potenciales.

Palabras clave: Prostitución. Trabajo del sexo. Estudios Organizacionales.

\section{INTRODUÇÃO}

O tema da prostituição aparece em publicações relacionadas com os Estudos Organizacionais (EO) no início da década de 1980, em conexão com a emergência dos Critical Management Studies (CMS) e com análises acerca da sexualidade predominantemente influenciadas pelo pós-estruturalismo (HEARN, 2011, 2014; BREWIS; TYLKER; MILLS, 2014). Além disso,

[...] embora o comércio do sexo constitua uma indústria globalmente interligada e efetivamente administrada, que oferece alta lucratividade em nível organizacional e para os proprietários, os debates acerca da essência de tal comércio têm levantado de modo 
surpreendente pouco interesse nos Estudos Organizacionais, em gestão e nos CMS (HEARN; HOLGERSSON; JYRKINNEN, 2015, p. 126).

Tendo encontrado essas indicações iniciais, pensamos que seria importante entender como o tema da prostituição tem sido abordado em periódicos reconhecidos no campo dos EO e quais as lacunas que persistem, além da já mencionada. Para isso, realizamos uma pesquisa em bases de dados. Ressalte-se que não se trata de um estudo bibliométrico ou de um estudo de revisão. A busca foi dirigida não apenas por palavras-chave, mas também para periódicos que são valorizados nesse campo de estudos. O termo de busca foi 'prostituição'. Na sequência, foi adicionado outro critério de busca, relacionando-o com trabalho, tendo em vista o movimento pelo reconhecimento da prostituição como trabalho do sexo. Não foi incluída nenhuma restrição temporal.

A pesquisa em periódicos nacionais foi feita através do Portal Scielo e resultou em um número pequeno de publicações em periódicos relacionados com os EO. A pesquisa em periódicos internacionais foi feita no Portal de Periódicos da Capes, SCOPUS, Sage e Wiley Pubs., assim como diretamente nos periódicos Organization e Gender, Work \& Organization, pela sua relevância nos EO. Além da maior quantidade, foram publicados no periódico Gender, Work \& Organization trabalhos de autores reconhecidos em termos de tempo dedicado ao tema, publicações e citações para o debate contemporâneo sobre a prostituição: O'Connell Davidson (1995); Brewis e Linstead (2000a, 2000b); e Sanders (2005).

Também foram considerados livros referidos nos artigos encontrados, com destaque para: Sex, Work and Sex Work: Eroticizing Organization (BREWIS; LINSTEAD, 2000c); Live Sex Acts: Women Performing Erotic Labor (CHAPKIS, 1997); Body/Sex/Work: Intimate, Embodied and Sexualized Labour (WOLKOWITZ et al., 2013); e Dirty Work (SIMPSON et al., 2012).

Tendo selecionado os trabalhos, foi realizada uma leitura interpretativa para reconhecer o tratamento dado ao tema da prostituição. Essa interpretação resultou na organização de três conjuntos: o primeiro compreende publicações que analisam a prostituição considerando aspectos relacionados à psicodinâmica; o segundo inclui textos que abordam os corpos e seus papeis em trocas que ocorrem em serviços comerciais de sexo, nos quais a prostituição está incluída; e o terceiro que compreende publicações que buscam analisar a relação da prostituição com as estruturas sociais e econômicas.

(c) (1) @ REAd | Porto Alegre - Vol. 27 - N. ${ }^{\circ} 1$ - Janeiro / Abril 2021 - p.66-92. 
Na sequência, se encontra a apresentação e discussão da presença do tema da prostituição em publicações relacionadas com os EO e as considerações finais, nas quais indicamos lacunas e potenciais desenvolvimentos.

\section{ABORDAGENS COM ÊNFASE EM ASPECTOS DA PSICODINÂMICA}

Duas das primeiras publicações sobre a sexualidade ocorreram no periódico Organization Studies e são creditadas a Hearn e Parkin (1983) e a Burrell (1984). Nelas, os autores analisaram a conexão entre processos de sexualidade e relações de trabalho em diferentes instâncias organizacionais a partir de aspectos de poder, controle e resistência (BREWIS; TYLKER; MILLS, 2014).

Burrell (1984, p. 100), em Sex and Organizational Analysis, aborda o desenvolvimento, nas sociedades industriais, de um processo de "dessexualização organizacional" que se efetiva na organização racional burocrática e no discurso estrutural-funcionalista dominante. Para o autor, o trabalho e a sexualidade são figurados como aspectos separados da vida e, nas relações de trabalho, opostos. Segundo Hearn (2011, p. 307), as consequências dessa cisão incluem a supressão da sexualidade e da dimensão erótica na análise das relações de trabalho. Essas, quanto mencionadas, apareciam de modo estrito e se referindo a temas como pornografia, prostituição e comércio sexual, sintetizados no texto com o uso do termo "sexploitation".

Foram, então, realizados estudos sobre os aspectos eróticos presentes nas relações de trabalho e a análise da indústria do sexo (sex industry) ${ }^{4}$ foi ampliada para fenômenos que eram (e, em parte, ainda são) vistos como excedentes à prostituição, tais como as terapias sexuais e as performances eróticas artísticas (BURRELL; HEARN, 1989; BREWIS; LINSTEAD, 2000b). Surgiu, assim, no espaço dos CMS, a vertente da sexualidade organizacional (organizational sexuality). Nela, a prostituição é mencionada como um fenômeno particular do trabalho sexual e tratada como uma das diferentes ocupações que lidam com aspectos eróticos, corporais e estéticos (HEARN, 2011).

\footnotetext{
${ }^{4}$ Indústria do sexo é a tradução literal de sex industry. No inglês, um dos significados de industry se refere a pessoas e atividades envolvidas em um setor de negócios. Sendo assim, sex industry se refere a atividades comerciais relacionadas a serviços sexuais, tais como prostituição, dança erótica, pornografia, tele-sexo etc.

(c) (1) @ REAd | Porto Alegre - Vol. 27 - N. ${ }^{\circ} 1$ - Janeiro / Abril 2021 - p.66-92.
} 
As publicações referentes a essa perspectiva, em periódicos dos EO, encontram-se sistematizadas no Quadro 1 e estão agrupadas em dois conjuntos: estudos internacionais que abordam a prostituição como uma forma de trabalho emocional, estético, erótico, entre outras derivações explicadas na sequência; e estudos desenvolvidos por autores brasileiros que estudam a prostituição em referência aos sentidos subjetivos do trabalho.

Quadro 1 - A prostituição e a psicodinâmica da sexualidade organizacional

\begin{tabular}{|c|c|c|c|}
\hline Tema & Texto & Autor & Periódico \\
\hline \multicolumn{4}{|c|}{ Publicações Internacionais } \\
\hline \multirow{6}{*}{$\begin{array}{c}\text { Trabalho } \\
\text { emocional } \\
\text { / estético/ } \\
\text { erótico/ } \\
\text { sexualiza- } \\
\text { do }\end{array}$} & $\begin{array}{l}\text { "The Worst Thing is the Screwing" (1) } \\
\text { Context and Career in Sex Work }\end{array}$ & $\begin{array}{l}\text { Brewis e } \\
\text { Linstead } \\
(2000 a)\end{array}$ & \multirow{5}{*}{$\begin{array}{l}\text { Gender, Work } \\
\text { \& Organization }\end{array}$} \\
\hline & $\begin{array}{l}\text { "The Worst Thing is the Screwing" (2) } \\
\text { Context and Career in Sex Work }\end{array}$ & $\begin{array}{l}\text { Brewis e } \\
\text { Linstead } \\
(2000 b)\end{array}$ & \\
\hline & $\begin{array}{l}\text { 'It's Just Acting': Sex Workers' Strategies } \\
\text { for Capitalizing on Sexuality }\end{array}$ & $\begin{array}{l}\text { Sanders } \\
(2005)\end{array}$ & \\
\hline & $\begin{array}{l}\text { What It Feels Like for a Whore: The Body } \\
\text { Politics of Women Performing Erotic Labour } \\
\text { in Hong Kong }\end{array}$ & $\begin{array}{l}\text { Kong } \\
(2006)\end{array}$ & \\
\hline & $\begin{array}{l}\text { Imagined and Embodied Spaces in } \\
\text { the Global Sex Industry }\end{array}$ & $\begin{array}{l}\text { Penttinen } \\
(2010)\end{array}$ & \\
\hline & $\begin{array}{l}\text { Putting sexualized labour in the picture: } \\
\text { Encoding "reasonable entitlement" in the lap } \\
\text { dancing industry }\end{array}$ & $\begin{array}{l}\text { Hales, } \\
\text { Riach e } \\
\text { Tyler } \\
(2019)\end{array}$ & Organization \\
\hline \multicolumn{4}{|c|}{ Publicações Nacionais } \\
\hline \multirow{2}{*}{$\begin{array}{l}\text { Sentidos } \\
\text { subjetivos } \\
\text { do } \\
\text { trabalho }\end{array}$} & $\begin{array}{l}\text { Sentidos do trabalho apreendidos por meio de } \\
\text { fatos marcantes na trajetória de mulheres } \\
\text { prostitutas }\end{array}$ & $\begin{array}{l}\text { Silva e } \\
\text { Cappelle } \\
(2015)\end{array}$ & $\begin{array}{l}\text { Rev. Adm. } \\
\text { Mackenzie }\end{array}$ \\
\hline & $\begin{array}{l}\text { O trabalho na prostituição de luxo: análise } \\
\text { dos sentidos produzidos por prostitutas em } \\
\text { Belo Horizonte }\end{array}$ & $\begin{array}{l}\text { Silva e } \\
\text { Cappelle } \\
(2017)\end{array}$ & $\begin{array}{l}\text { Revista de } \\
\text { Gestão Social e } \\
\text { Ambiental }\end{array}$ \\
\hline
\end{tabular}




\begin{tabular}{|l|l|c|c|}
\hline & $\begin{array}{l}\text { "O show tem que continuar": encalços e } \\
\text { percalços do ser/estar prostituta }\end{array}$ & $\begin{array}{c}\text { Pereira et } \\
\text { al. } \\
(2018)\end{array}$ & $\begin{array}{c}\text { Revista } \\
\text { Contemporânea } \\
\text { de Economia e } \\
\text { Gestão }\end{array}$ \\
\cline { 2 - 5 } & $\begin{array}{l}\text { Entre o sagrado e o profano: identidades, } \\
\text { paradoxos e ambivalências de prostitutas } \\
\text { evangélicas do baixo meretrício de Belo } \\
\text { Horizonte }\end{array}$ & $\begin{array}{c}\text { Pereira et } \\
\text { al. } \\
(2020)\end{array}$ & $\begin{array}{c}\text { Cadernos } \\
\text { EBAPE. } \\
\text { BR }\end{array}$ \\
\cline { 2 - 5 } & $\begin{array}{l}\text { Mulheres de vida fácil? Tempo, prazer e } \\
\text { sofrimento no trabalho de prostitutas }\end{array}$ & $\begin{array}{c}\text { Paiva et al. } \\
\text { (2020) }\end{array}$ & $\begin{array}{c}\text { Administração } \\
\text { de Empresas }\end{array}$ \\
\hline
\end{tabular}

Fonte: elaborado pelos autores.

No primeiro conjunto, a prostituição é considerada como um tipo específico de trabalho em que se destacam os aspectos emocional, corporal, estético e erótico. Nesse conjunto se encontram os trabalhos mais citados e autores reconhecidos no contexto anglo-saxão dos EO, com destaque para Brewis e Linstead (2000a, 2000b, 2000c).

Segundo Fleming (2007), essa linha de trabalho foi influenciada pela popularidade dos estudos sobre biopoder e sexualidade realizados por Michel Foucault (1995, 1997, 1999) no final da década de 1970, por autores como Deleuze e Guattari (2004) e, posteriormente, Judith Butler (1997, 2000). Para Brewis e Grey (1994), eles questionam proposições que demarcavam o erotismo e a sexualidade a partir de critérios biológicos e ressaltam que o desenvolvimento desses aspectos da vida ocorre de modo contingencial a relações de poder e epistemes locais.

Inspirada por essas ideias, surgiu a perspectiva da sexualidade organizacional e da reerotização, que instauraram análises sobre o trabalho sexual. Fundamentando-se na crítica à hipótese repressiva elaborada por Foucault (1999), Brewis e Grey (1994) argumentam que a perspectiva da re-erotização supera proposições libertárias e revolucionárias da sexualidade baseadas em Reich (1981) e Marcuse (1999), ao enfatizar relações de poder que não possuem um domínio geral e defender um ativismo de desconstrução e transgressão dessas relações e dos saberes a elas atrelados para que os indivíduos habitem modos mais livres de existir. 
Segundo Cohen et al. (2013), essa perspectiva impactou de modo peculiar a compreensão acerca da prostituição, que deixou de ser concebida como uma atividade essencialmente exploratória e destruidora da personalidade para ser analisada como um fenômeno de relações de emprego e processos de trabalho que envolvem a mercantilização e a individualização do corpo, das emoções e da sexualidade.

Nessa perspectiva, a prostituição é analisada em processos de embodiment. São discutidas as concepções estáticas, biológicas e naturalistas do corpo e abordado seu papel em processos contingenciais de subjetivação. Os autores usualmente situam relações difusas de poder que reverberam na constituição corpórea de pessoas assujeitadas que tomam os esquemas difundidos nas estratégias biopolíticas (de biopoder) como próprios. Para exemplificar essa compreensão, segue a o trecho da análise de Pentinnen (2010, p. 31) sobre a indústria global do sexo, na qual a globalização é considerada como uma forma de biopoder que produz subjetividades genderizadas e etnicizadas:

Foucault explica que o poder subjetivante opera de três maneiras: primeiro, ao nomear o sujeito; segundo, por meio de práticas divisórias que diferenciam o normal e o anormal; terceiro, ao transformar os indivíduos em sujeitos. Foucault argumenta que o poder subjetiva os indivíduos ao subordiná-los, mas também os transforma em sujeitos autônomos, amarrando-os a uma identidade própria. Butler desenvolve essa discussão sobre indivíduos se transformando em sujeitos, teorizando onde e como essa transformação ocorre e quais são suas implicações em termos de agência. Ela mostra que tornar-se sujeito, ou seja, sujeitar-se ao poder, é desejável, pois proporciona reconhecimento como sujeito e, assim, também agência. Butler explica que o poder sempre precede o sujeito. Ele atua no sujeito, mas esse poder é uma forma de ativação e ela ativa o sujeito no ser. A subjetividade internalizada é embodied e desempenhada por meio do corpo, mas a interpretação da individualização do poder não é pré-determinada, e essa quebra proporciona a ligação da agência inerente nos processos de subjetivação.

Inserindo-se nessa perspectiva, Brewis e Linstead (2000b, p. 174) argumentam que as pessoas em situação de prostituição tomam para si "identidades profissionais" que as auxiliam a conquistar clientes, proporcionar maior aferimento de renda e diminuir os impactos da mercantilização do corpo e da personalidade. Nessa lógica, a prostituição é vista sob a ótica da incorporação provisória de estilos profissionalizantes e gerenciais que proporcionam maior controle na interação com clientes pelo domínio de práticas e ideias relacionadas ao

[...] marketing, contabilidade, planejamento de negócios, gestão de propriedade, controle financeiro, promoção, empreendedorismo, conhecimento legislativo, habilidades políticas, educação, atuação, aconselhamento e gestão de recursos humanos, mesmo sem 
considerar aquelas mais ligadas à arte erótica (ars erótica) da qual a profissão é fundada (BREWIS; LINSTEAD, 2000b, p. 168-169).

Considerando que o trabalho realizado por Brewis e Linstead (2000c) é muito difundido e utilizado como referência, suas proposições são apresentadas em mais detalhes nos próximos parágrafos.

Além de aspectos gerenciais, Brewis e Linstead (2000c, p. 4) destacam que as pessoas podem atuar, na prostituição, como agentes transgressores no que intitulam "duplo efeito discursivo" da organização do trabalho do sexo, isto é, esquemas que polarizam fenômenos do trabalho sexual entre os extremos da necessidade e abjeção e da profissionalização e perversão. Para os autores, o trabalho do sexo

[...] é o ponto crucial entre a sexualidade e a organização. Isso ocorre porque encontramos o trabalho do sexo sujeito a uma dupla rejeição - a primeira na construção discursiva da sexualidade "normal" em virtude de ser comercializada e organizada e, portanto, inautêntica; a segunda na construção discursiva da organização porque é sexual e, portanto, ilegítima. O trabalho do sexo, portanto, captura e constitui um exemplo de uma categoria de ser psicológico e social que é um elemento importante em nossa compreensão dos processos do desejo - o abjeto (BREWIS; LINSTEAD, 2000c, p. 1).

Apesar de situar a prostituição no interior da polarização entre organização (concebida como trabalho) e sexualidade, Brewis e Linstead (2000b) destacam que na relação entre trabalho sexual e prostituição, a última explicita o território adicional e liminar da sexualidade normalizada e autêntica. Para esses autores, a comercialização do desejo sexual realizada na indústria do sexo "assombra as fronteiras da organização", pois "[...] parece confundir princípios organizacionais tão importantes como diferenciação, ordem, regulação, padronização, estabilidade e até mesmo tamanho", ao mesmo tempo em que tensiona os limites do que pode ser publicamente comercializado e privativamente resguardado (BREWIS; LINSTEAD, 2000c, p. 13).

Essas proposições indicam uma análise dos aspectos liminares e contingenciais da prostituição com base nas variações espaciais e temporais dos discursos que objetivam corpos e comportamentos e que subjetivam seres de sexualidade e de trabalho. Dessa maneira, a própria noção de organização pode ser re-erotizada: "Esse tipo de re-erotização não é apenas emancipatória, mas transgressora, não apenas das formas organizacionais, mas potencialmente da própria ideia de organização" (BREWIS; LINSTEAD, 2000c, p. 182).

Segundo Brewis e Linstead (2000c, p. 202), Deleuze e Guattari (2004) sugerem que 
[...] a prostituta pode potencialmente desempenhar uma função radical e politizada, pois o desejo circula em oposição ao capitalismo, ao mesmo tempo que emprega, combina e descarta as formas culturais capitalistas - as botas, as meias, o corpete - para intensificar a sensação. Estar simplesmente envolvido no trabalho sexual é, portanto, potencialmente libertador e transgressivo.

Utilizam, também, a análise sobre a fragmentação do desejo de Lyotard (1974). Com esses aportes, definem as pessoas em situação de prostituição como "ativistas da resistência" e empreendedores da indústria do consumo que, ao se profissionalizarem, resguardam aspectos essenciais de sua personalidade e desempenham existências dissidentes em relação ao que é estabelecido como normal (BREWIS; LINSTEAD, 2010c, p. 202). Com base nas proposições de Foucault (1997), Brewis e Linstead (2010c) destacam que as modalidades contemporâneas de sadomasoquismo, com destaque para as que não estão voltadas para a penetração e a dominação de pessoas afeminadas, especulam novos modelos de organização e abrem campo para outras identidades pessoais e profissionais.

Para West e Austrin (2002), essa perspectiva pressupõe que as relações de trabalho que envolvem aspectos eróticos e de sexualidade apresentam um aspecto contingencial da organização social do desejo em que habitam diferentes posições, em um contínuo que vai de atividades exclusivamente necessárias e profissionais a atividades abjetas, imorais e perversas. Esses estudos enfatizam o caráter contingencial dos diferentes fenômenos da indústria do sexo e ressaltaram trocas dissonantes com os consumidores, sem estabelecer suas ligações com o contexto geral. $\mathrm{O}$ foco no desejo e na "psicodinâmica da sexualidade organizacional" tem, de acordo com West e Austrin (2002, p. 490), como finalidade exclusiva a difusão de identidades que desconsideram estrutura sociais mais amplas: "[...] o interesse pelo trabalho e a produção convencional é especificamente abandonado pela afirmação de que sua preocupação é em como o sentido particular de organização é produzido, especificamente no sentido de nós mesmos como seres sexuais".

Na revisão dos periódicos, também foram identificados estudos realizados no Brasil e que compartilham a análise sobre os sentidos subjetivos produzidos no ato da troca comercial que se concretiza na prostituição. Silva e Cappelle (2015) adotam o conceito de sentidos subjetivos do trabalho, desenvolvido por Rey (2003), para destacar os processos simbólicos e emocionais que legitimam uma produção subjetiva a partir dos sentidos que os indivíduos atribuem ao próprio 
trabalho. Nesse estudo, as autoras identificam que as prostitutas incorporam aspectos de violência, insegurança e imoralidade. Em outro estudo, Silva e Capelle (2017) inspiram-se em Vygotsky (1991), Dejours (2000) e Morin (2002) para analisar a produção de sentidos na psicodinâmica da prostituição no mercado de luxo. Concluíram que a interação com os clientes é uma relação mercadológica na qual são constituídas diferentes identidades e fantasias. Esses sentidos se intersectam com os estigmas negativos atrelados à prostituição e impactam as relações extratrabalho dos participantes, com destaque para as relações familiares.

Pereira et al. (2018) analisam, em Belo Horizonte, como os sentidos atribuídos à prostituição se constituíam no processo de identificação e construção identitária. As análises revelam que a constituição subjetiva dos participantes da pesquisa reflete o modo frágil e fragmentado como percebem o atuar na prostituição, principalmente por ela estar atrelada a uma forma de trabalho sujo (PEREIRA et al., 2018). Em outro estudo, Pereira et al. (2020) analisam, também em Belo Horizonte, a construção identitária de prostitutas evangélicas e identificam que elas incorporam os estigmas negativos relacionados à atividade e potencializados pela moralidade religiosa.

Já Paiva et al. (2020, p. 216) analisam a influência de percepções acerca do tempo nas vivências de prazer e sofrimento, novamente em Belo Horizonte. Esse estudo identificou que os participantes concebem os aspectos temporais como algo que pode ser mercantilizado, controlado e precificado em função do período e velocidade de realização dos programas. Essas duas dimensões do tempo, período e velocidade, remetem a um aspecto de prazer que é o aferimento mais célere de renda, ou seja, ao "processo latente de empoderamento" pelo dinheiro. A maior duração da atividade é considerada uma fonte de sofrimento relacionada ao desgaste físico e mental, às demandas por terceiros para que realizem maior quantidade de programas em menos tempo, e aos impactos de atuação numa atividade que é concebida como uma forma de trabalho sujo, imoral e pecaminoso. Para os autores, os participantes vivenciam, na prostituição, mais situações de sofrimento do que de prazer, e essa desproporção gera crises e fragmentações identitárias.

\section{A PROSTITUIÇÃO COMO UM SERVIÇO COMERCIAL DE SEXO}

(c) (1) @ REAd | Porto Alegre - Vol. 27 - N. ${ }^{\circ} 1$ - Janeiro / Abril 2021 - p.66-92. 
$\mathrm{Na}$ busca realizada também foram encontrados trabalhos que abordam os corpos e seus papeis em interações que ocorrem em serviços comerciais de sexo, nos quais a prostituição, que se distingue por ser um serviço sexual direto (HARDY, 2013), está incluída. No Quadro 2 se encontra uma sistematização de temas e autores, deixando claro que se referem à prostituição, mas também a atividades como dança erótica, pornografia, terapia sexual etc.

Quadro 2 - Interações em serviços comerciais de sexo

\begin{tabular}{|c|c|c|}
\hline Temas & Autores principais & Aspectos Principais \\
\hline $\begin{array}{l}\text { Trabalho } \\
\text { emocional }\end{array}$ & $\begin{array}{l}\text { Hochschild (2012), } \\
\text { Chapkis (1997), } \\
\text { Brents e Jackson } \\
(2013)\end{array}$ & $\begin{array}{l}\text { Os trabalhadores interagem com os clientes e evocam, } \\
\text { neles, um estado emocional. Ajustam as emoções para } \\
\text { atender às normas e expectativas culturais, relacionadas à } \\
\text { exibição emocional. A prostituição é concebida e } \\
\text { valorada positivamente tendo em vista um aspecto duplo: } \\
\text { o cuidado terapêutico e de satisfação de necessidades } \\
\text { físicas e emocionais dos consumidores. Remete também } \\
\text { ao aspecto profissionalizante, no qual, durante a } \\
\text { realização dos programas, são criados personagens para } \\
\text { resguardar aspectos essenciais da personalidade e } \\
\text { capitalizar. }\end{array}$ \\
\hline $\begin{array}{l}\text { Trabalho erótico/ } \\
\text { sexualizado }\end{array}$ & $\begin{array}{l}\text { Warhurst e Nickson } \\
(2009), \text { Sanders } \\
(2005), \text { Kong } \\
(2006)\end{array}$ & $\begin{array}{l}\text { As interações sexualizantes ou erotizantes produzem uma } \\
\text { identidade desejável. O trabalho sexualizado é, portanto, } \\
\text { transformador da identidade, indo além da estética. Para } \\
\text { essa vertente, no exercício da prostituição as pessoas } \\
\text { redefinem a própria sexualidade, que é distinta e } \\
\text { propositalmente separada de sua identidade em outros } \\
\text { espaços, como nas suas vidas sexuais românticas íntimas } \\
\text { e nas relações familiares e de amizade. }\end{array}$ \\
\hline Trabalho corporal & $\begin{array}{l}\text { Crossley (1995), } \\
\text { Twigg (2000), Kang } \\
\text { (2003), Wolkowitz } \\
(2006)\end{array}$ & $\begin{array}{l}\text { Revela a natureza material e corporificada da ação nos } \\
\text { corpos de outrem. Envolve o cuidar, reparar, dar prazer, } \\
\text { estetizar, treinar ou controlar o corpo de usuários e } \\
\text { clientes. Nessa lógica, a prostituição é tratada como parte } \\
\text { dos serviços nos quais são desenvolvidos processos de } \\
\text { aprendizagem tátil e simbólica, tal como ocorre na } \\
\text { enfermagem, odontologia, estéticas, ioga e em serviços } \\
\text { de segurança. Desse modo, a prostituição é socialmente } \\
\text { construída nos agenciamentos internos da indústria do } \\
\text { sexo com determinações mais amplas do corpo social } \\
\text { relacionadas predominantemente à sexualidade e classe. }\end{array}$ \\
\hline Intercorporeidade & $\begin{array}{l}\text { Crossley (1995), } \\
\text { Hales, Riach e Tyler } \\
\text { (2019) }\end{array}$ & $\begin{array}{l}\text { Essa vertente aborda a situação na qual modos } \\
\text { condicionados de perceber o mundo externo são } \\
\text { materializados na interação significativa entre as pessoas. } \\
\text { Essa materialização se dá em seus corpos e } \\
\text { comportamentos, que trazem à existência cenários } \\
\text { refratados desse mundo externo. Pessoas em situação de } \\
\text { prostituição desempenham, provisoriamente, } \\
\text { subjetividades particulares ao articular, nessas }\end{array}$ \\
\hline
\end{tabular}




\begin{tabular}{|l|l|l|}
\hline & $\begin{array}{l}\text { configurações mercadológicas, seus corpos e capacidades } \\
\text { afetivas. }\end{array}$ \\
\hline $\begin{array}{l}\text { Trabalho } \\
\text { corpóreo e } \\
\text { estético }\end{array}$ & $\begin{array}{l}\text { Tyler e Taylor } \\
\text { (1998), Wolkowitz } \\
(2006), \text { Witz, } \\
\text { Warhurst e Nickson } \\
(2003), \text { Warhurst e } \\
\text { Nickson (2009) }\end{array}$ & $\begin{array}{l}\text { Os corpos dos trabalhadores fazem parte do hardware } \\
\text { organizacional. Eles mobilizam, desenvolvem e } \\
\text { mercantilizam disposições corporificadas por meio de } \\
\text { processos de recrutamento, seleção e treinamento, } \\
\text { transformando-os em habilidades que são voltadas para a } \\
\text { produção de estilos de serviço. Analisa a corporalidade } \\
\text { de trabalhadores na interação estabelecida com } \\
\text { consumidores. Nessa vertente, os corpos são } \\
\text { estrategicamente geridos, com ênfase na aparência e no } \\
\text { comportamento para apelar aos sentidos dos clientes e } \\
\text { cumprir requisitos mercadológicos. }\end{array}$ \\
\hline Trabalho sujo & $\begin{array}{l}\text { A prostituição é considerada um trabalho insalubre e } \\
\text { Asheshes (1962), } \\
\text { imoral. A identidade das pessoas em situação de } \\
\text { prostituição é constituída em cenários estigmatizados e } \\
\text { hierarquizados por aspectos relacionados à sexualidade } \\
\text { em geral, a estigmas particulares da prostituição e a } \\
\text { (2004), Grandy e } \\
\text { Mavin (2012) }\end{array}$ \\
\hline
\end{tabular}

Fonte: organizado com o apoio de Cohen (2019) e Hardy (2013).

$\mathrm{Na}$ abordagem do trabalho emocional, a atividade é concebida e valorizada positivamente com referência a um aspecto terapêutico que remete ao cuidado e satisfação das necessidades físicas e emocionais dos consumidores; ao mesmo tempo em que inclui um aspecto profissionalizante, já que no contexto de realização dos programas são resguardados aspectos essenciais da personalidade e a trocas são condicionadas de acordo com suas finalidades econômicas (BRENTS; JACKSON, 2013). Essa noção de trabalho foi desenvolvida por Hochschild (2012) para enfatizar o gerenciamento das emoções e a criação, por pessoas que realizam serviços que lidam diretamente com usuários e clientes (p. ex., os comissários de bordo), de uma corporalidade publicamente observável. Segundo a autora, o exercício emocional de cuidar dos outros e de si confere aos prestadores de determinado serviço um valor de uso que é comercializado por um salário e, portanto, possui um valor de troca. Seguindo essas ideias, Chapkis (1997, p. 75) defende que, na prostituição, é realizada uma gestão corpórea e psíquica que contribui para que as emoções sejam mercantilizadas de modo controlado, a exemplo do trabalho realizado por atores, psicoterapeutas e enfermeiros. Em suas palavras: “[...] para trabalhadores do sexo, a habilidade de convocar (summon) e conter a emoção durante a transação comercial pode ser experimentada mais como uma ferramenta útil para a manutenção de limites do que como uma perda do self'. 
Foram também encontrados textos nos quais a atividade é concebida como uma forma de trabalho estético, no sentido de que os atributos físicos são utilizados para criar personagens que estimulam eroticamente os consumidores (WARHURST; NICKSON, 2009). Essa perspectiva, segundo Hardy (2013), identifica a prostituição como uma gestão estratégica do corpo e da aparência cuja finalidade é apelar aos sentidos e cumprir requisitos mercadológicos, a exemplo do cuidado estético realizado por pessoas que trabalham no comércio de alta costura e em serviços ligados à indústria de feiras e do entretenimento noturno. Sanders (2005) utilizou as categorias de trabalho emocional e estético para evidenciar processos de manufatura identitária. Ou seja, no contexto de realização dos programas são criados mecanismos de autoproteção contra o estresse ocorrido durante a venda do sexo. Além disso, é adotado um discurso profissionalizante para atrair e manter a clientela, e capitalizar por meio da sexualidade. Entre as estratégias descritas estão a criação de zonas de exclusão corpóreas, como, por exemplo, a proibição do beijo; a criação de barreiras psicológicas de contato carnal e de fluidos, como o uso de preservativos; e a realização de serviços de dominação (dominatrix). Para a autora, esses modos de desempenhar são estratégias de negócio e criam uma mercantilização situacional benéfica e positiva para as pessoas no exercício da prostituição.

$\mathrm{Na}$ abordagem trabalho corporal são tratadas as estratégias de gestão do corpo (WOLKOWITZ, 2006). Segundo Hardy (2013), essa perspectiva considera os contatos corporais íntimos e traz à tona a relação material e simbólica existente entre o servidor e o cliente, tal como ocorre em serviços de assistência social e estética. Nessa lógica, a prostituição é tratada como parte dos serviços que estimulam processos de aprendizagem háptica (tátil) e simbólica, a exemplo dos serviços de massagem e da anamnese médica (COHEN et al., 2013). De modo similar, alguns estudos a concebem como um trabalho sexual interativo que remete aos jogos realizados entre as pessoas em situação de prostituição e usuários pela cobrança e acesso tátil ao corpo, tal como ocorre nos serviços de dança erótica e striptease (CHAPKIS, 1997; SANDERS, 2005).

Hales, Riach e Tyler (2019) analisam a intercorporeidade a partir da fenomenologia existencialista proposta por Merleau-Ponty (1994). As autoras estudam como as subjetividades e configurações organizacionais que constituem uma modalidade de dança erótica chamada de lap dancing (ou dança de colo) moldam as experiências vividas durante as interações íntimas com os clientes. Ao fazê-lo, identificaram como as publicidades presentes em filmes e sites relacionados ao lap dancing são percebidas e, posteriormente, codificadas, incorporadas e incrustadas 
(embedded) nos programas por pessoas em situação de prostituição. Essa perspectiva defende que a subjetividade se constitui em organizações situacionais e contingenciais e, portanto, a organização é concebida como a situação na qual modos condicionados de perceber o mundo externo são materializados em interações significativas. Assim, essa materialização em corpos e comportamentos traz à tona a existência de cenários refratados do mundo externo. No cenário analisado por Hales, Riach e Tyler (2019, p. 2), as propagandas condicionam um "embodiment organizacional" a partir do qual as pessoas se constituem subjetivamente e agem como objetos a serem consumidos. Ao fazê-lo, desempenham, provisoriamente, subjetividades particulares que articulam, nessas configurações mercadológicas, seus corpos e capacidades afetivas. Para complementar essa análise, as autoras utilizam a analítica performativa de Butler (2010) para fundamentar o caráter efêmero dessa constituição subjetiva. Nesse sentido, as pessoas se subjetivam como uma mercadoria somente no contexto dos programas, quando incorporam e refratam desempenhos particulares que são demandados pela indústria do sexo e, na intercorporeidade, realizam, um trabalho emocional, corpóreo e estético (HALES; RIACH; TYLER, 2019).

Outra perspectiva é a do trabalho sujo, influenciada por autores do interacionismo simbólico, em especial pelo trabalho de Hughes (1962). Ashforth e Kreiner (1999) analisam a construção identitária de trabalhadores de atividades que são socialmente percebidas como nojentas ou degradantes, a exemplo de ocupações que lidam com o lixo, a morte e efluentes, assim como aquelas que são realizadas em condições perigosas ou nocivas. Segundo os autores, os aspectos físicos, sociais e morais associados a essas ocupações estigmatizam os trabalhadores, que podem internalizar esses aspectos negativos ou os converter em fatores de resistência:

[...] o estigma do trabalho sujo torna o papel do trabalho per se saliente, e a ameaça incorporada no estigma promove uma forte coesão e o surgimento de uma cultura ocupacional ou de grupo de trabalho, que ajuda a combater a ameaça. Quanto mais forte a ameaça, mais forte é a cultura e mais as percepções de "nós contra eles" são reforçadas. Uma cultura forte fornece os recursos sociais para reformular, recalibrar e redirecionar o significado do trabalho sujo - ou seja, para fomentar ideologias enobrecedoras. As ideologias do trabalho sujo muitas vezes glorificam precisamente aqueles aspectos do trabalho que são mais estigmatizados (ASHFORTH; KREINER, 1999, p. 428).

Segundo Grandy e Mavin (2012), esses processos ocorrem também em uma estrutura que é composta e sobreposta por hierarquias de sexo, estigmas particulares à atividade e ao trabalho sujo. Assim, o tema da prostituição não é relacionado com a comercialização, mas com estigmas 
sociais. Desse modo, os fatores relacionados a estigmas negativos ou positivos fazem com que as pessoas que se prostituem se construam e sejam socialmente vistas como outros trabalhadores que realizam atividades estigmatizadas (KONG, 2006).

\section{EM BUSCA DAS ESTRUTURAS SOCIAIS DA PROSTITUIÇÃO}

Finalmente, trazemos os estudos que se propõe a analisar a relação entre prostituição e estruturas sociais, e que são muito influenciados pelos trabalhos de O'Connell Davidson (1995) e de West e Austrin (2002). Em periódicos relacionados aos EO e abordando o tema da prostituição concebida como trabalho do sexo, foram encontradas duas publicações desses autores: The Anatomy of 'Free Choice' Prostitution' (O'CONNELL DAVIDSON, 1995) e From work as sex to sex as work: Networks, 'others' and occupations in the analysis of work (WEST; AUSTRIN, 2002) - ambas em Gender, Work \& Organization.

Segundo Ekman (2015), O’Connell Davidson é uma das principais referências europeias no tema da prostituição e tráfico de pessoas para finalidades de exploração sexual. Apesar de ter publicado somente uma vez em periódico do campo dos EO, esse artigo é referido em quase todos os estudos revisados. Sua obra é conhecida por criticar a polarização entre a vertente liberal, que defende o reconhecimento da prostituição como trabalho do sexo, e o neoabolicionismo, que defende a abolição da prostituição. Essa crítica enfatiza a relação entre as desigualdades econômicas e as restrições de ordem extraeconômica que estão presentes em diferentes modalidades de prostituição (WEST; AUSTRIN, 2002).

Para O’Connell Davidson (2015), há um extremo que é composto por pessoas em situação de prostituição que ingressam na atividade devido a limitações econômicas e/ou foram marginalizadas em função de estética, raça, sexualidade, gênero, nacionalidade, entre outros aspectos. As pessoas que habitam esse extremo têm suas possibilidades de agência fortemente limitadas e participam de modalidades de prostituição que se aproximam de formas recentes de escravidão, como o tráfico sexual. O outro extremo é composto por pessoas que ingressam na atividade por cumprirem requisitos estético-comportamentais de mercados de luxo e possuem maior liberdade de atuação na indústria do sexo. Entre esses extremos ocorrem diferentes modalidades de prostituição. Essas variações no exercício da atividade se relacionam com processos de valorização existentes na totalidade da formação socioeconômica capitalista.

(c) $\frac{(1) \Theta(8)}{\text { ar }}$ REAd | Porto Alegre - Vol. 27 - N..$^{\circ} 1$ - Janeiro / Abril 2021 - p.66-92. 
Em The anatomy of "free choice" prostitution, O'Connell Davidson (1995) realiza um estudo etnográfico para investigar o tema da livre escolha de pessoas em situação de prostituição que atuavam de modo autônomo (também chamadas de empreendedoras). Após identificar que as pessoas participantes do estudo possuíam um certo controle e poder de negociação com os clientes, a autora argumenta que o neoabolicionismo expressa uma noção simplista e essencialista da atividade, concebendo-a como uma forma de escravidão assalariada e desconsiderando ingressantes que não se encontram em situação de radicais restrições econômicas e possuem possibilidades de agência, mesmo que limitadas.

Ao se referir ao que denomina de modelo liberal, O’Connell Davidson (1995) argumenta que ele também concebe a atividade de modo abstrato, ao considerar que os programas ocorrem nos moldes de trocas voluntárias análogas às relações de trabalho existentes nos setores do entretenimento e da hotelaria. A valorização, na indústria do sexo, ocorre de modo relativamente diferente do trabalho em geral, pois a troca de dinheiro por sexo é, em essência, estigmatizada. O argumento é que, apesar do aumento de investimentos nessa indústria, o estigma do sexo se mantém e se constitui em uma pré-condição e finalidade dessa troca peculiar.

O conceito de valor [na prostituição] pressupõe a troca, e serviços sexuais, diferente da força de trabalho humana, não são geralmente trocados. Nas sociedades capitalistas, a norma é vender a força de trabalho e as pessoas não são desonradas por temporariamente "terceirizarem" esta forma de "propriedade" em sua pessoa. Mas os atos sexuais não são tipicamente vistos como mercadorias, e a sexualidade não é plenamente regulada pela ideologia do mercado. Em vez disso, um conjunto complexo de ideias pré-capitalistas e não mercantis - incluindo honra, vergonha, amor, prazer, lealdade - geralmente governam a interação sexual das pessoas. Prostitutas e clientes são socializados em um mundo no qual significados particulares são vinculados à sexualidade humana (significados que sustentam os códigos e convenções que governam a interação sexual), um mundo no qual é amplamente sustentado que o único sexo legítimo é entre homens e mulheres que amam uns aos outros e que "dinheiro não compra amor". Ao comprar o acesso à "propriedade sexual" que uma prostituta tem em sua pessoa, o cliente leva a prostituta a um mundo social marginal no qual "'serviços sexuais" são considerados como tendo um valor de troca e no qual não se aplicam os códigos e convenções 'normais' que regulam a interação entre parceiros sexuais. A vida profissional da prostituta, portanto, ocorre em um espaço entre dois mundos, incompletamente dominado pela ideologia do mercado livre e, ainda assim, separado dos valores e códigos pré-mercado (O'CONNELL DAVIDSON, 1995, p. 9).

Para O'Connell Davidson (1995, p. 8), a prostituição não possui “[...] um valor de troca significativo e mensurável". O motivo apresentado pela autora é que pessoas mercantilizam algo "[...] que é socialmente construído como parte integrante de sua identidade, sua honra, sua posição na sociedade" (O'CONNELL DAVIDSON, 1995, p. 9). Nessa proposição, a prostituição habita 
um espaço liminar entre as determinações econômicas e as da sexualidade. Essa posição impede que a atividade seja plenamente mercantilizada e que as pessoas que vendem os corpos e a personalidade o façam como qualquer mercadoria ou forma de serviço, já que os valores associados à troca sexual íntima são pressupostos nessa troca. Assim, o componente do estigma é uma parte necessária e inerente que, no metabolismo com o dinheiro, é provisoriamente escamoteado. Segundo O’Connell Davidson (1994), o dinheiro é o principium movens que desloca a prostituição a esse mudo liminar que parece ser livre dos códigos e convenções existentes nos encontros sexuais não comerciais. Parece ser possível que as pessoas consigam, no ato de prostituir-se, alienar temporariamente partes do corpo e renunciar aos desejos pessoais e eróticos sem consequências.

Além disso, ela argumenta que na aparência de uma relação contratual ${ }^{5}$ voluntária, profissional e neutra, o valor que se consuma na prostituição parte da estigmatização e tem, nela, uma finalidade inerente. Nessa lógica, “[...] o sustento da prostituta realmente depende da manutenção da própria ideologia que a degrada e a torna uma pária social. Seu status liminar como uma pessoa que não é uma pessoa é, simultaneamente, a fonte de seu estigma e de sua subsistência" (O’CONNELL DAVIDSON, 1995, p. 9). Além disso, “[...] uma quantia substancial de dinheiro não necessariamente compra uma saída do estigma e suas consequências sociais e psicológicas" (O’CONNEL DAVIDSON, 1995, p. 9).

A divergência da autora em relação aos modelos que denomina liberal e neoabolicionista é sustentada pelo seu diagnóstico da liminaridade da prostituição (BREWIS e LINSTEAD, 2000b). O modo de superar a abstração - como escravidão assalariada ou como trabalho assalariado como qualquer outro - seria adotar uma estratégia mista que leve em conta as duas proposições, mas as articule de um modo que, no curto e médio prazo, proporcione melhores condições de realização da atividade, principalmente por meio da conquista de direitos trabalhistas, e, no longo prazo, efetive meios de extinção do comércio do sexo como um todo (O’CONNEL DAVIDSON, 2003). Essa estratégia híbrida, segundo Gall (2006, p. 27), parece questionar a polarização, mas a assume ao se posicionar em um contínuo entre as duas posições.

\footnotetext{
5 A crítica à lógica liberal e contratualista de mercado usualmente proferida pelos defensores do trabalho do sexo é creditada a Pateman (1988). Segundo a autora, a ilusão de uma relação contratual igualitária na prostituição esconde as finalidades da exploração capitalista. Como uma relação de consumo, discute também que o cliente da prostituição não a toma como uma relação quantitativa e meio para novas trocas e valorizações, mas objetiva o uso qualitativo e o consumo final.
} 
Sendo assim, apesar de se declarar parcial e provisoriamente favorável às demandas da regularização da prostituição, O’Connell Davidson (1998) defende que há aspectos essenciais à atividade que fazem com que ela deva ser extinta. Um deles é a já mencionada estigmatização. $\mathrm{O}$ outro é que a ação coletiva realizada por pessoas em situação de prostituição é inerentemente fraca por estar inserida em relações de consumo em que não haveria produção de mais-valia. Nesse sentido, as pessoas possuiriam menor poder de barganha com terceiros e com os clientes.

Segundo West e Austrin (2002), essa autora erra ao realizar esse diagnóstico, pois o faz, a exemplo da perspectiva da sexualidade organizacional, a partir da interação entre pessoas em situação de prostituição e clientes, ignorando instituições que atuam no nível meso e macro na indústria do sexo, como as diferentes instâncias do aparelho de Estado e investidores poderosos da indústria do sexo que lucram com a atividade. Gall (2006, p. 57) argumenta que

[...] como West aponta, esta análise é comprometida por sua concentração e conceituação de um aspecto específico da prostituição, aquele da interação entre a prostituta independente e o cliente (apesar de considerações anteriores de O'Connell Davidson (1998) sobre a prostituição com o envolvimento de terceiros, como bordéis e agências, bem como os pontos de alavancagem estabelecidos em seu estudo sobre uma prostituta empreendedora). Mas, o mais importante no caso da prostituição independente, é que O'Connell Davidson confunde o consumo com o que é de fato a produção e a realização do valor de serviço por prostitutas (por meio da negociação). Esses processos criam uma relação de interdependência com o consumidor e, assim, pontos de alavancagem para prostitutas. Apesar da prostituta ser frequentemente responsável pela troca de um modo atomizado (tal como uma prostituta independente ou quando o terceiro não determina o preço), a troca deve necessariamente ser baseada na produção de "trabalho" e não está desprovida de um contexto coletivo que define socialmente a "taxa atual".

Para o autor, essa insuficiência é superada pela análise da ação coletiva de pessoas em situação de prostituição, que deve entrecruzar "[...] terrenos meso e macro e níveis gerais e específicos" (GALL, 2006, p. 222). Esse seria o modo de incluir o tema no estudo "[...] dos processos de acumulação e troca, identidades, ideologia, trabalho, mercados e regulação dentro das dinâmicas e formas do capitalismo" (GALL, 2006, p. 222). Nesses terrenos, o autor argumenta em prol da organização coletiva como meio mais sensato para que as pessoas em situação de prostituição conquistem um valor social e exerçam maior controle da sua atividade.

Em outra vertente de análise, West e Austrin (2002) também criticam O’Connell Davidson por se ater ao nível micro da relação. Para superar essa insuficiência, se posicionam com base em proposições de autores pertencentes à Escola de Chicago, como Becker (1963) e Hughes (1971). Para West e Austrin (2002), essa tradição permite pensar a prostituição como uma organização em (c) (1) @ REAd | Porto Alegre - Vol. 27 - N. ${ }^{\circ} 1$ - Janeiro / Abril 2021 - p.66-92. 
rede, composta por diferentes laços e grupos de interesse que disputam entre si o controle da atividade. Nessa lógica, cada entrelaçamento constitui uma modalidade diferente de prostituição e produz dinâmicas particulares que variam "[...] conforme o ambiente de atuação e os discursos específicos de trabalho, consumo, de gênero e sexualidade” (WEST; AUSTRIN, 2002, p. 499).

Hardy (2013), por sua vez, destaca que a prostituição envolve processos de intercorporeidade. No entanto, o faz de maneira distinta da vertente registrada anteriormente, afirmando que na prostituição se expressam relações entre os agenciamentos internos da indústria do sexo com as determinações mais amplas de sexualidade e classe. Para exemplificar essa dinâmica, relata a estratégia sindical adotada por algumas organizações que defendem a prostituição como trabalho do sexo para criar uma identidade intercorpórea que sintetiza a exploração sexual e de classe, ao mesmo tempo em que cria um meio para ingressar na luta trabalhista e pela libertação sexual.

\section{CONSIDERAÇÕES FINAIS}

O tema da prostituição em publicações do campo dos EO foi apresentado neste artigo em três conjuntos de textos.

O primeiro inclui aspectos relacionados à psicodinâmica. Os estudos que encontramos em periódicos internacionais se vincula à perspectiva da re-erotização. Nele se encontram autores que analisam a prostituição na ótica da psicodinâmica da sexualidade organizacional e focalizam em processos de construção identitária que ocorrem na interação entre pessoas em situação de prostituição e seus clientes. Essa perspectiva concebe essas interações, predominantemente, em sua particularidade. Abordam, também, como diferentes organizações condensam modos locais e contingenciais de existir na indústria do sexo e como ocorre o controle dos saberes acerca da atividade e das possibilidades de agência. A prostituição é concebida como um exercício do corpo e das emoções, de maneira que as pessoas se conduzam, no mercado, de um modo mais livre e menos danoso como resultado do domínio dos instintos e da criação de personagens mercantilizáveis que, em situações menos condicionadas da atividade, possibilitariam transgredir matrizes de inteligibilidade ou sistemas hierárquicos da sexualidade.

No primeiro conjunto incluímos os estudos publicados no Brasil. É importante destacar que ainda que compartilhem uma construção semelhante do tema de estudo, eles se distinguem pela 
referência à psicodinâmica do trabalho e, dessa maneira, expressam de maneira mais objetiva o cotidiano das pessoas em situação de prostituição, apontam as contradições e os sofrimentos a ela relacionados, bem como os sentidos produzidos.

O terceiro conjunto se refere a diversas atividades de interação em serviços sexuais comerciais, incluindo o serviço sexual direto que se concretiza na prostituição. A ampliação do espectro de atividades consideradas possibilita ampliar os temas em busca de respostas para a pergunta sobre o que é vendido nesse encontro de serviços, centrando no corpo como aspecto central.

O terceiro conjunto de publicações busca relacionar as modalidades da prostituição com aspectos socioeconômicos. Nele se destacam as proposições de O’Connell Davidson (1995). A autora se refere, de modo superficial e com equívocos conceituais, à teoria marxista do valor, articulando-a com a perspectiva da liminaridade para compreender a prostituição no espaço liminar e interseccional entre as determinações da economia e da sexualidade.

Esses estudos, apesar de suas diferenças e com exceção dos trabalhos publicados no Brasil, apresentam alguns aspectos em comum: (a) assumem, ainda que em alguns de modo implícito, a prostituição como trabalho do sexo e/ou como serviços eróticos e da sexualidade que seguem uma lógica comercial e de mercado; (b) enfatizam análises dos indivíduos em suas particularidades e condutas; (c) secundarizam o cotidiano da atividade em busca de aspectos transgressores dos limites da sexualidade; (d) não questionam as relações de mercado per se, mas buscam modos de nelas existir de modo mais livre; e (f) apresentam uma noção individualista da atividade e de formas de resistências.

Essa constatação expressa a influência de analíticas pós-estruturalistas que inserem o tema da prostituição nos fenômenos da sexualidade moderna e subordinam o tema do trabalho do sexo a essa compreensão. Nessa perspectiva, a prostituição aparece como uma das práticas e saberes que exaltam os processos de diferenciação e singularização da sexualidade. Um dos aspectos fundamentais é o enfoque na individualidade particularizante e o rechaço ao caráter social dos modos de resistir às opressões. O social aparece como uma conexão vazia, abrindo campo para o arbítrio sobre os fundamentos e movimentos de subjetivação e embodiment. Em consequência, as proposições expressam modos relativistas e contingenciais de compreensão. Assim, processos de resistência aos condicionamentos da prostituição ocorrem dentro de limites que excluem a possibilidade de transcender a ordem do presente.

(c) $\stackrel{(1) \Theta(}{)} \operatorname{REAd} \mid$ Porto Alegre - Vol. 27 - N..$^{\circ} 1$ - Janeiro / Abril 2021 - p.66-92. 
Isso se constata, inclusive, nos estudos que tentam incluir a relação entre aspectos econômicos e de sexualidade, mas que o fazem sem historicidade, tratando-os de modo autonomizado nos espaços liminares e interseccionais. Essa aproximação fica evidente, por exemplo, no fato de que tanto autores de referência na perspectiva da re-erotização (BREWIS; LINSTEAD, 2010c), quanto a autora de referência na tentativa de realizar uma aproximação com a economia política (O’CONNELL DAVIDSON, 1995) mencionam valorizam o mito da livre escolha e valorizam o empreendimento como uma expressão do exercício de uma certa autonomia.

Uma lacuna evidente que se encontra nessas abordagens e nos processos e proposições que se orientam pela afirmação da prostituição como trabalho do sexo é a ausência de reflexões e discussões sobre o trabalho. Qual é o significado de trabalho na expressão "trabalho do sexo"? Dessa lacuna decorre a ausência de temas extensivamente abordados no campo da organização e da sociologia do trabalho, tais como controle, alienação, exploração ${ }^{6}$. As publicações que aqui registramos não apenas contribuem para um tratamento superficial do tema, como naturalizam o trabalho explorado que passa a ser, inclusive, uma condição desejada. Sem abordar o tema do trabalho para além de sua aparência fenomênica, é possível afirmar que a emancipação das pessoas em situação de prostituição poderia se dar por meio de um reconhecimento da condição que se constitui, no sistema do capital, no fundamento da opressão e da exploração: o trabalho alienado e o estranhamento.

Rainieri (2006, p. 178)) esclarece que o conceito de alienação se refere a uma exteriorização que o ser humano autoproduz e que se forma no interior de sua sociabilidade. É, portanto, traço inerente ao ser humano em suas relações sociais. O estranhamento, por sua vez, designa as "[...] insuficiências de realização do gênero humano decorrentes das formas históricas de apropriação do trabalho", incluindo a própria personalidade, assim como as condições objetivas engendradas pela produção e reprodução da vida. No sistema do capital, a alienação aparece como um "fenômeno concêntrico ao estranhamento" porque "obstáculos sociais impedem que a atividade de exteriorização, inerente aos seres humanos, se realize em conformidade com suas potencialidades". Abordar essa dimensão exigiria problematizar "a aceitação do cotidiano da vida como algo inelutável, irrevogável", evitaria tratar emancipação e resistência subordinando-os aos nexos

\footnotetext{
${ }^{6}$ Apenas de maneira ilustrativas, mencionamos Grupos de Pesquisa (GP) que abordam alguns desses temas: GP Economia Política do Poder em Estudos Organizacionais (UFPR); Núcleo de Estudos Organizacionais, Sociedade e Subjetividade (CEFET-MG); GP Estudos dos Coletivos de Trabalho e das Práticas Organizacionais (UFF); GP Estudos Críticos do Trabalho e Marxologia (UFMG).
}

(c) (1) $\left(\right.$ REAd | Porto Alegre - Vol. 27 - N. ${ }^{\circ} 1$ - Janeiro / Abril 2021 - p.66-92. 
internos da reprodução das relações sociais de produção que geram as privações e as várias opressões.

Problematizar a prostituição a partir dessa posição teórico-política não implica negar que podem existir formas de proteção a partir da legislação e da organização que propiciem alguma forma de proteção e tornem as condições do exercício cotidiano da atividade mais seguras. Tratase de reconhecer a complexidade e as contradições que estão presentes nessa concepção, assim como nas relações de mercado e de agenciamento por terceiros, incluindo aspectos relacionados aos direitos humanos, ao tráfico de pessoas, ao abuso de menores. Ou seja, reconhecer que podem existir demandas transicionais que instituam proteções às pessoas em situação de prostituição e que, simultaneamente, fortaleçam sua organização. No entanto, ao fazê-lo, evitar a falácia de que por esse caminho se produz a emancipação ou se resiste às determinações da ordem social.

Para finalizar, rememoramos Alexandra Kollantai (1980). Escrevendo no início do século XX e no contexto da Revolução Russa, ela defendeu uma moralidade sexual comunista de relações de amor e camaradagem livres e abertas. Relações entre iguais, relações não mercantilizadas e não possessivas. Para tanto, a emancipação das mulheres é indispensável, e requer sua libertação da dependência financeira de indivíduos homens e de relações patriarcais de propriedade ${ }^{7}$. Ou seja, a luta ideológica sobre gênero e relações sexuais se faz simultaneamente com as lutas econômicas e sociais. Especificamente sobre a prostituição, reconhecia sua existência como um meio necessário de subsistência e criticava "a hipocrisia da sociedade burguesa, que encoraja a prostituição pela estrutura de sua economia exploradora, e ao mesmo tempo cobre de desprezo cada menina ou mulher que é forçada a seguir esse caminho" (KOLLANTAI, 1980, p. 263).

Em um tempo no qual o desejo tende a ser reificado, autonomizado das relações materiais de existência e das relações sociais que nelas se constituem e se expressam, o que importa são os circuitos individuais de expressão e gratificação. Nesse tempo, a exploração do trabalho ganha ares de liberdade de escolha (como na precarização via plataformas ou no mantra do empreendedorismo), o mercado vai se instituindo como uma distopia total em que se compra e vende corpos e representações de corpos, muitas vezes em processos de opressão obscurecidos por

\footnotetext{
${ }^{7}$ Ebert (1999) destaca que, embora a articulação das relações humanas elaborada por Kollantai era heterossexual (ela fala em relações entre os sexos), a sua visão de relações pós-patriarcais, de relações abertas e não monogâmicas, abre a possibilidade para uma sociedade radicalmente pós-heterossexual.

(c) $(1) \Theta$ REAd | Porto Alegre - Vol. 27 - N. ${ }^{\circ} 1$ - Janeiro / Abril 2021 - p.66-92.
} 
abordagens que afirmam a possibilidade de subverter a moralidade por práticas que promovem a gratificação individual e o consumismo.

Esperamos que as informações que trouxemos sobre as abordagens do tema da prostituição nos EO, e as considerações críticas que realizamos ao final, contribuam para que se ampliem os diálogos com os estudos sobre o trabalho e que se produzam contribuições desde uma perspectiva crítica, sem cair em armadilhas dicotômicas e sem naufragar no imediatismo do presente.

\section{REFERÊNCIAS}

ASHFORTH, B. E.; KREINER, G. "How can you do it?”: dirty work and the challenge of constructing a positive identity. Academy of Management Review, v. 24, n. 3, p. 413-434, jul. 1999.

BECKER, H. Outsiders: studies in the sociology of deviance. New York: Free Press, 1963.

BOLTON, S. Emotion management in the workplace. London: Palgrave Macmillan, 2004.

BRENTS, B. G.; JACKSON, C. A. Gender, emotional labour and interactive body work: negotiating flesh and fantasy in sex worker's labour practices. In: WOLKOWITZ, C. et al. (ed.). Body/sex/work: intimate, embodied and sexualised labour. Hampshire: Palgrave Macmillan, 2013. p. 77-92.

BREWIS, J.; GREY, C. Reeroticizing the organization: an exegesis and critique. Gender, Work \& Organization, v. 1, n. 2, p. 67-82, 1994.

BREWIS, J.; LINSTEAD, S. "The worst thing is the screwing" (1): consumption and the management of identity in sex work. Gender, Work \& Organization, v. 7, n. 2, p. 84-97, 2000a.

BREWIS, J.; LINSTEAD, S. "The worst thing is the screwing" (2): context and career in sex work. Gender, Work \& Organization, v. 7, n. 3, p. 168-180, 2000 b.

BREWIS, J.; LINSTEAD, S. Sex, work and sex work: eroticizing organization. London: Routledge, 2000c.

BREWIS, J.; TYLER, M.; MILLS, A. Sexuality and organizational analysis - 30 years on: Editorial introduction. Organization, v. 21, n. 3, p. 305-311, 2014.

BURRELL, G. Sex and organizational analysis. Organization Studies, v. 5, n. 2, p. 97-118, 1984. 
BURRELL, G.; HEARN, J. The sexuality of organization. In: HEARN, J. et al. (ed.). The sexuality of organization. London: Sage, 1989. p. 1-28.

BUTLER, J. The psychic life of power: Theories in subjection. Redwood: Stanford University Press, 1997.

BUTLER, J. Problemas de gênero: feminismo e subversão da identidade. Rio de Janeiro: Civilização Brasileira, 2010.

CHAPKIS, W. Live sex acts: women performing erotic labor. New York: Routledge, 1997.

COHEN, R. L. Types of work and labour. In: GALL, G. (ed.) Handbook of the politics of labour, work and employment. Cheltenham: Edward Elgar, 2019, p. 261-281.

COHEN, R. L. et al. The body/sex/work nexus: a critical perspective on body work and sex work. In WOLKOWITZ, C. et al. (Eds.). Body/sex/work: intimate, embodied and sexualised labour. Hampshire: Palgrave Macmillan, 2013. p. 3-27.

CROSSLEY, N. Body techniques, agency and intercorporeality: on Goffman's relations in public. Sociology, v. 29, n. 1, p. 133-149, 1995.

DELEUZE, G.; GUATTARI, F. Mil Platôs: capitalismo e esquizofrenia.Vol. 3. Rio de Janeiro: Editora 34, 2004.

DEJOURS, C. Travail, usure mentale: nouvelle edition augmentée. Paris: Bayard, 2000.

EBERT, T. L. Left of desire. Cultural Logic, v.5, p. 1-24, 1999. Disponível em: https://doi.org/10.14288/clogic.v5i0.192637. Acesso em: 13 set. 2000.

EKMAN, K. E. EU project hijacked by the prostitution lobby. Ressources on prostitution, 2015. Disponível em: https://ressourcesprostitution.wordpress.com/2015/09/04/kajsa-ekisekman-eu-project-hijacked-by-the-prostitution-lobby/. Acesso em: 13 de fev. de 2020.

FLEMING, P. Sexuality, power and resistance in the workplace. Organization Studies, v. 28, n. 2, p. 239-256, 2007.

FOUCAULT, M. O sujeito e o poder. In; DREYFUS, H.; RABINOW, P. (ed.) Michel Foucault, uma trajetória filosófica. Rio de Janeiro: Forense Universitária, 1995. p. 231-249.

FOUCAULT, M. Sex, power, and the politics of identity. In RABINOW, P. (ed.). Essential works of Foucault 1954-1984. Ethics: subjectivity and truth. Vol. 1. New York: The New Press,1997, p. 163-174.

FOUCAULT, M. História da Sexualidade 1: A Vontade de Saber. São Paulo: Edições Graal (Original Publicado em 1976), 1999. 
GALL, G. Sex worker union organising: an international study. Hampshire: Palgrave MacMillan, 2006.

GOFFMAN, E. Estigma: notas sobre a manipulação da identidade. Porto Alegre: LTC, 1981.

GRANDY, G.; MAVIN, S. Doing gender in dirty work: Exotic dancers' construction of selfenhancing identities. In: SIMPSON, R. et al. (ed..). Dirty work: concepts and identities. London: Palgrave Macmillan, 2012. p. 91-112.

HARDY, K. Equal to any other, but not the same as any other: the politics of sexual labour, the body and intercorporeality. In: WOLKOWITZ, C. et al. (ed.). Body/sex/work: intimate, embodied and sexualised labour. Hampshire: Palgrave Macmillan, 2013. p. 43-58.

HALES, S.; RIACH, K.; TYLER, M. Putting sexualized labour in the picture: encoding "reasonable entitlement" in the lap dancing industry. Organization, v. 26, n. 6, p. 783-801, 2019.

HEARN, J. Sexualities, work, organizations, and managements: Empirical, Policy, and Theoretical Challenges. In: JEANES, E.; KNIGHTS, D.; MARTIN, P. Y. (ed..). Handbook of Gender, Work \& Organization. Chichester: Wiley, 2011. p. 299-314.

HEARN, J. Sexualities, organizations and organization sexualities: future scenarios and the impact of socio-technologies (a transnational perspective from the global 'north'). Organization, v. 21, n. 3, p. 400-420, 2014.

HEARN, J.; PARKIN, W. Gender and organizations: a selective review and a critique of a neglected area. Organization Studies, v. 4, n. 3, p. 219-242, 1983.

HEARN, J.; HOLGERSSON, C.; JYRKINEN, M. Sexualities and/ in 'critical' management studies. In PRASAD, A. et al. (Eds.). The Routledge companion to critical management studies. Oxon: Routledge, 2015. p. 124-139.

HOCHSCHILD, A. R. The managed heart: commercialization of human feeling. Berkley: University of California Press, 2012.

HUGHES, E. C. Good people and dirty work. Social problems, v. 10, n. 1, p. 3-11, 1962.

KANG, M. The managed hand: the commercialization of bodies and emotions in Korean immigrant owned nail salons. Gender and Society, v. 17, n. 6, p. 820-839, 2003.

KOLLANTAI, A. Selected writings of Alexandra Kollantai. New York: Vintage, 1980.

KONG, T. What it feels like for a whore: the body politics of women performing erotic labour in Hong Kong. Gender, Work \& Organization, v. 13, n. 5, p. 409-434, 2006.

LYOTARD, J. Economie libidinale. Paris: Éditions de Minuit, 1974.

(c) (1) @ REAd | Porto Alegre - Vol. 27 - N. ${ }^{\circ} 1$ - Janeiro / Abril 2021 - p.66-92. 
MARCUSE, H. Eros e civilização: uma interpretação filosófica do pensamento de Freud. Rio de Janeiro: LTC, 1999.

MERLEAU-PONTY, M. Fenomenologia da percepção. São Paulo: Martins Fontes, 1994.

MORIN, E. Os sentidos do trabalho. In: WOOD, T. (ed.). Gestão empresarial: o fator humano. São Paulo, SP: Atlas, 2002. p. 13-34.

O'CONNELL DAVIDSON, J. The sources and limits of resistance in a privatized utility. In: JERMIER, J. M.; KNIGHTS, D. E.; NORD, W. R. (ed.). Resistance and power in organizations. London: Taylor \& Frances/Routledge, 1994. p. 69- 101.

O'CONNELL DAVIDSON, J. The anatomy of "free choice" prostitution. Gender, Work \& Organization, v. 2, n. 1, p. 1-10, 1995.

O’CONNELL DAVIDSON, J. Prostitution, power, and freedom. Detroit: University of Michigan Press, 1998.

O’CONNELL DAVIDSON, J. Sleeping with the enemy? Some problems with feminist abolitionist calls to penalise those who buy commercial sex. Social Policy and Society, v. 2, n. 1, p. 55, 2003.

O’CONNELL DAVIDSON, J. Modern slavery: The margins of freedom. New York: Springer, 2015.

PAIVA, K. et al. Mulheres de vida fácil? Tempo, prazer e sofrimento no trabalho de prostitutas. Revista de Administração de Empresas, v. 60, n. 3, p. 208-221, 2020.

PATEMAN, C. The Sexual Contract. Cambridge: Polity Press, 1988.

PENTTINEN, E. Imagined and embodied spaces in the global sex industry. Gender, Work \& Organization, v. 17, n. 1, p. 28-44, 2010.

PEREIRA, J. R. et al. 'O Show tem que continuar': encalços e percalços do ser/estar prostituta. Contextus - Revista Contemporânea de Economia e Gestão, v. 16, n. 3, p. 151-180, 2018.

PEREIRA, J. R. et al. Entre o sagrado e o profano: identidades, paradoxos e ambivalências de prostitutas evangélicas do baixo meretrício de Belo Horizonte. Cadernos EBAPE.BR, Rio de Janeiro, v. 18, n. 2, p. 391-405, 2020.

RAINIERI, J. Alienação e estranhamento: a atualidade de Marx na crítica contemporânea do capital. Ideias, v. 12-12, p. 177-192, 2006.

REICH, W. A revolução sexual. 7. Rio de Janeiro: Zahar, 1981. 
REY, F. Sujeito e subjetividade: uma aproximação histórico-cultural. São Paulo: Pioneira Thomson Learning, 2003.

SANDERS, T. "It's just acting": sex workers' strategies for capitalizing on sexuality. Gender, Work \& Organization, v. 12, n. 4, p. 319-342, 2005.

SILVA, K.; CAPPELLE, M. Sentidos do trabalho apreendidos por meio de fatos marcantes na trajetória de mulheres prostitutas. Revista de Administração Mackenzie, v. 16, n. 6, p. 19-47, 2015.

SILVA, K.; CAPPELLE, M. O trabalho na prostituição de luxo: análise dos sentidos produzidos por prostitutas em Belo Horizonte - MG. Revista de Gestão Social e Ambiental, v. 11, n. esp., p. 23-39, 2017.

SIMPSON, R. et al (ed.). Dirty work: concepts and identities. Hampshire: Palgrave Macmillan, 2012.

TYLER, M.; TAYLOR, S. The exchange of aesthetics: women's work and "The Gift"'. Gender, Work \& Organization, v.5, n. 3, p. 165-71, 1998.

TWIGG, J. Bathing: the body and community care. London: Routledge, 2000.

VYGOTSKY, L. S. Obras escogidas II: problemas de psicología general. Madrid: Visor Distribuciones, 1991.

WARHURST, C.; NICKSON, D. 'Who's got the look?': emotional, aesthetic and sexualized labour in interactive services. Gender, Work \& Organization, v. 16, n. 3, p. 385-404, 2009.

WITZ, A., WARHURST, C.; NICKSON, D. The labour of aesthetics and the aesthetics of organization. Organization, v. 10, n. 1, p. 33-54, 2003.

WEST, J.; AUSTRIN, T. From work as sex to sex as work: networks, 'others' and occupations in the analysis of work. Gender, Work \& Organization, v. 9, n. 5, p. 482-503, 2002.

WOLKOWITZ, C. Bodies at work. London: Sage, 2006.

WOLKOWITZ, C.; WARHURST, C. Embodying labour. In: THOMPSON, P.; SMITH, C. (ed..). Working Life. Basingstoke: Palgrave MacMillan, 2010. p. 223-243.

WOLKOWITZ, C. et al. (ed.). Body/sex/work: intimate, embodied and sexualised labour. Hampshire: Palgrave Macmillan, 2013. 